\title{
Contêiner refrigerado: uma alternativa para a conservação pós-colheita de alface tipo americano.
}

\author{
Bárbara J. Terueli'; Luís A. B. Cortez ${ }^{2}$ Lincoln C. Neves Filho ${ }^{3}$ \\ ${ }^{1}$ UNICAMP-FEM, Área Interdisciplinar de Planejamento de Sistemas Energéticos, C. Postal. 6122, 13.081-970. Campinas - SP; \\ ${ }^{2}$ UNICAMP-FEAGRI, Dep ${ }^{\text {to }}$ de Construções Rurais, C. Postal 6011; ${ }^{3}$ UNICAMP-FEA, Dep ${ }^{\text {to }}$ de Engenharia dos Alimentos, C. Postal \\ 6121. e-mail: barbara@fem.unicamp.br
}

\section{RESUMO}

A refrigeração é um excelente método para o armazenamento prolongado de produtos frescos. O uso de contêineres na agricultura é uma tecnologia simples e de fácil utilização que permite a manutenção da qualidade de produtos frescos, como frutas e hortaliças e a diminuição das perdas pós-colheita. Neste trabalho foram desenvolvidos uma série de experimentos com um contêiner frigorífico submetido a dois regimes de operação: vazio e com produto. Foram avaliadas as seguintes variáveis: temperatura, velocidade e umidade relativa do ar, além da pressão do sistema de refrigeração. Foi determinado o tempo de meio resfriamento de alface tipo americano (Latuca sativa L.), submetido a uma temperatura de $1^{\circ} \mathrm{C}$. Nas superfícies que recebem maior radiação solar o desvio da temperatura é de $1,5 \pm 1^{\circ} \mathrm{C}$, com respeito às paredes que recebem menor radiação. A velocidade do ar variou de 2,$1 ; 1,7$ e $0,3 \mathrm{~m} / \mathrm{s}$, nos três planos estudados. $\mathrm{O}$ tempo de meio resfriamento da carga de alface variou entre $530 \mathrm{~min}(» 8 \mathrm{~h}$ ), e $1.080 \mathrm{~min}$ (» $18 \mathrm{~h}$ ), dependendo da posição das cabeças de alface no interior do contêiner. A umidade relativa do ar foi de $81-86 \% \pm 1 \%$ e de $90-91 \pm 1 \%$, para o contêiner vazio e com carga, respectivamente.

Palavras-chave: Latuca sativa L., armazenamento, refrigeração, eficiência.

\begin{abstract}
Refrigerated container: an alternative for postharvest conservation.

Refrigeration is an excellent method for storing horticultural fresh products such as fruits and vegetables. The use of refrigerated containers is a simple and ready-to-use technology allowing better quality and decreasing postharvest losses. In this work some experiments were conducted with a refrigerated container in two operating conditions: with and without load. The following variables were evaluated: air temperature, air velocity, air relative humidity, and pressure of the refrigeration system. The lettuce (Latuca sativa L.) half-cooling time was also determined when this product was stored at $1^{\circ} \mathrm{C}$. It was observed that the container surfaces receiving more radiation presented temperature increases of $1,5 \pm 1^{\circ} \mathrm{C}$ in contrast to the surfaces that were less exposed. Air speed ranged from $2.1 ; 1.7$ and $0.3 \mathrm{~m} / \mathrm{s}$ for the three studied surfaces. The lettuce half-cooling time varied from $530 \mathrm{~min}$ and $1.080 \mathrm{~min}$, depending on the position of the head of lettuce in the container. The relative humidity of the air was $81-86 \% \pm 1 \%$ in the empty container and $90-91 \pm 1 \%$, for the loaded container.
\end{abstract}

Keywords: Latuca sativa L., storage, refrigeration, efficiency.

\section{(Aceito para publicação em 02 de maio de 2.000)}

$\mathrm{O}$ Brasil é um dos maiores produtores de frutas e hortaliças, mas apresenta um pequeno volume de exportação. A safra de 1990 representou de acordo com dados da FAO (1991), 8\% da produção mundial. Mesmo assim, os valores das perdas pós-colheita são significativamente altos, reportando-se uma média de $30-40 \%$ da produção total, com um valor estimado de mais de
US\$ 1/kg (Brasil, 1993). Entre as principais causas destas perdas estão o uso de embalagens inadequadas, falta de transporte adequado e a ausência de refrigeração para o armazenamento, ex- 
pondo os produtos a condições desfavoráveis (Neves Filho. et. al., 1995).

O armazenamento de produtos agrícolas em câmaras móveis e modulares (contêineres frigoríficos), é uma tecnologia interessante visto as vantagens que possui, como possibilidade de ser transportado de um local para outro, sistema de aluguel (sistema leasing) durante a safra, ampla faixa de temperaturas de operação do sistema (entre -25 e $25^{\circ} \mathrm{C}$ ) e facilidade de operação. Estes contêineres também podem ser usados no transporte dos produtos já refrigerados (Figueredo, 1995). Tais vantagens representam menores custos, possibilitando o armazenamento dos produtos durante a safra, quando os preços são mais baixos, para sua posterior comercialização, diminuindo assim as flutuações do mercado e colaborando na formação de um estoque regulador. O uso de contêineres frigoríficos na agricultura é uma alternativa técnica e econômica interessante quando se trata de curtos períodos de estocagem, em função da diminuição do tempo de exposição dos produtos a condições desfavoráveis de temperatura e umidade (Figueredo, 1995).

No presente trabalho avaliou-se um contêiner para determinar as possibilidades de seu uso diretamente no local de colheita, para possível armazenamento ou resfriamento de produtos agrícolas.

\section{MATERIAL E MÉTODOS}

Para atingir os objetivos propostos foram desenvolvidas duas etapas: avaliação do comportamento da temperatura, umidade e velocidade do ar no interior do contêiner e dos principais parâmetros de trabalho do sistema frigorífico (com o contêiner vazio), e uma segunda etapa, onde foi feita a avaliação do comportamento da temperatura e da umidade do ar com o contêiner submetido à carga real (resfriamento de alface tipo americano). Também foi determinado o tempo de meio resfriamento, o que permitiu avaliar o comportamento do contêiner para fins de resfriamento rápido. Para atingir os objetivos foram realizadas as seguintes medidas:

- temperatura e pressão de trabalho do sistema frigorífico do contêiner (etapa I);
- velocidade do ar no interior do contêiner (etapa I);

- temperatura do ar no interior do contêiner e no centro dos produtos (etapa II);

- temperatura de bulbo úmido no interior do contêiner (para a determinação da umidade relativa do ar) (etapa I e II).

Para o desenvolvimento da pesquisa foi usado um contêiner refrigerado com um volume interno de $26 \mathrm{~m}^{3}$, de procedência inglesa, marca G9 NU, modelo 137B- 234, e construção exterior de painéis de aço. $\mathrm{O}$ isolamento térmico é poliuretano expandido com uma espessura de $76 \mathrm{~mm}$ e o piso é de alumínio com canaletes que permitem a circulação e distribuição do ar, insuflado pela parte inferior, retornando ao evaporador pela parte superior do contêiner (evaporador com 2 ventiladores; 0,43 kW [1,4 A/ $220 \mathrm{~V}]$; sistema de degelo com resistência elétrica de $0,5 \mathrm{~kW}$ ).

A unidade frigorífica (marca CARRIER, compressor 06 DR 337 semi-hermético; 5kw [22,2 A/220 V]; $1.750 \mathrm{rpm}$; capacidade frigorífica $\mathrm{Qo}=$ $10.500 \mathrm{~W}$ ). A condensação é a ar operando com refrigerante R-12, instalada na parte traseira do contêiner (1 ventilador; $0,74 \mathrm{~kW}$; [1 A/220 V]; 1.425 rpm). Os sistema está equipado com um controlador-registrador de temperatura acoplado ao termostato de forma a registrar a temperatura no interior do contêiner durante 31 dias.

O contêiner foi colocado sob condições de intempérie, ao lado do Laboratório de Máquinas da Faculdade de Engenharia Agrícola (FEAGRI), ficando assim exposto às radiações solares, simulando as condições reais em que poderiam ser usados

Para realizar a medição da temperatura foram utilizados termopares tipo "T" (Cobre-Constantan) AGW №. 24, revestidos de PVC, construídos e calibrados $\left( \pm 0,10{ }^{\circ} \mathrm{C}\right)$, no Laboratório de Refrigeração da Faculdade de Engenharia dos Alimentos, FEA (Teruel, 1996).

Foram instalados 11 termopares no interior do contêiner, distribuídos entre as paredes, piso, teto, porta, insuflamento do ar frio e retorno do ar ao evaporador (Figura 1). Um termopar foi colocado na parte exterior do contêiner,

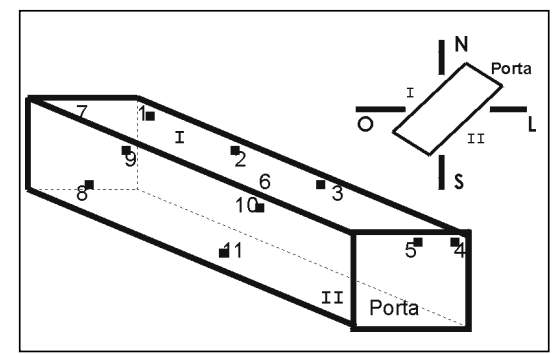

Figura 1. Distribuição dos pontos em que foram colocados os termopares no interior do contêiner. Campinas, UNICAMP, 1995.

para medir a temperatura do ar ambiente, ou exterior (text).

Para a avaliação do desempenho do sistema frigorífico foram instalados 5 termopares nos seguintes pontos: saída da válvula de expansão termostática (temperatura de evaporação, to), linha de sução do compressor (temperatura de sução, ts), linha de descarga do refrigerante (temperatura de descarga do compressor, td), linha de saída do refrigerante do condensador (temperatura de condensação, tcond).

O monitoramento da temperatura foi feito utilizando um sistema de aquisição de dados por computador, que consta de uma placa analógica digital PCX 0802 e um conversor de sinais CAD 12/ 32 (com 32 canais de aquisição). O sistema de aquisição de dados foi instalado num computador AT 486. A leitura e armazenamento dos dados foi feito com o software AQDADOS (fornecido pela LYNX Tecnologia Eletrônica Ltda.). Para facilitar o ordenamento da coleta dos dados, os termopares foram numerados para ser conectados ao conversor de sinais.

Para a medição das pressões de trabalho do sistema de refrigeração, foi instalado um conjunto de manômetros da marca Imperial, com escala de até $3.447 \mathrm{kPa}$ (500 psi) na descarga (manômetro de alta pressão) e $1.378 \mathrm{kPa}$ (200 psi) na sucção (manômetro de baixa pressão).

Para avaliar o desempenho termodinâmico do sistema frigorífico alguns parâmetros foram calculados, usando os dados de temperatura e pressão determinados experimentalmente no sistema, e as equações da termodinâmica. Destes parâmetros o fabricante não possuía informações, 
dentre eles, a eficiência volumétrica do compressor $\left(\eta_{\mathrm{v}}\right)$ :

$$
\eta_{v}=\frac{\dot{v_{d r}}}{\dot{v}_{d t}}
$$

onde, $\dot{v}_{\mathrm{dr}}$ e $\dot{v}_{\mathrm{dt}}$ são o volume de deslocamento real e teórico do R-12 no compressor $\left(\mathrm{m}^{3} / \mathrm{s}\right),\left[\dot{\mathrm{v}}_{\mathrm{dr}}=\dot{\omega}_{\mathrm{r}} \mathrm{v}\right]$, $\dot{\omega}_{\mathrm{r}}$ e o fluxo mássico de R-12 (kg/s), u é o volume específico $\left(\mathrm{m}^{3} / \mathrm{kg}\right)$; $\left[\dot{v}_{\mathrm{dt}}=\frac{\pi \mathrm{d}_{\mathrm{p}}^{2}}{240}\right], \mathrm{d}_{\mathrm{p}}$ é o diâmetro do pistão do compressor (m).

Eficiência do ciclo de refrigeração (Performance Coefficient, COP):

$$
\mathrm{COP}=\frac{\Delta \mathrm{h}_{\mathrm{o}}}{\Delta \mathrm{h}_{\text {comp }}}
$$

onde, $\Delta \mathrm{h}_{\mathrm{o}}$ e $\Delta \mathrm{h}_{\text {comp }}$, são as diferenças de entalpia na entrada e saída do evaporador e do compressor $(\mathrm{kJ} / \mathrm{kg})$. A entalpia foi determinada traçando o ciclo termodinâmico no diagrama termodinâmico Mollier.

Foi determinado também o grau de superaquecimento do refrigerante, entre a saída do evaporador e a sução do compressor, a diferença de temperatura entre a condensação do refrigerante e a temperatura do ar exterior, e a diferença entre a temperatura de evaporação do refrigerante e a temperatura do ar no interior do contêiner $(\Delta \mathrm{T}=\mathrm{tc}-\mathrm{to})$.

A velocidade do ar foi medida com um anemômetro eletrônico digital de ventoinha, marca Lutron, modelo AM4201. As leituras foram tomadas em 9 pontos, em três planos diferentes obtidos da divisão do contêiner em três áreas iguais (I, II, III). Os pontos 1, 2 e 3 estão no nível inferior (na linha de insuflamento do ar do evaporador, limite com as canaletes do piso, plano I); os pontos 4, 5 e 6 na linha média (centro do contêiner, plano II) e os pontos 8,9 e 10 na parte superior do contêiner (coincidindo com a porta, no sentido do retorno do ar ao evaporador, plano III) (Figura 2). Essa distribuição permitiu obter um perfil do comportamento da velocidade do ar no interior do contêiner. O piso foi coberto em $70 \%$ de sua área com lâminas metálicas para simular a circulação do ar com o contêiner carregado e evitar o retorno do ar ao evaporador logo após o insuflamento.

Para a determinação da umidade relativa, foram utilizados dois termopares medindo as temperaturas do bulbo úmido no insuflamento do ar frio e no retorno ao evaporador, e dois termopares nestes mesmos pontos medido a temperatura do ar (bulbo seco). Para a medição da temperatura do bulbo úmido foi colocada uma mecha de tecido na ponta do termopar e introduzida num bulbo com água destilada. Este método já tinha sido testado com bons resultados (Teruel, 1996). Com os valores da temperatura de bulbo úmido e de bulbo seco, obtidos durante o monitoramento, foram determinados os valores da umidade relativa do ar no interior do contêiner, com auxilio do software Plus (Albright, 1990).

Os ensaios foram realizados no mês de julho, iniciando-se às 11:00 h e com duração de 26 horas, fazendo-se duas repetições, porém os valores referenciados neste trabalho correspondem às médias das medições experimentais. A temperatura fixada no termostato do contêiner foi de $0^{\circ} \mathrm{C}$ (tc). As condições psicrométricas do ar exterior ao início do ensaio foram: tbs = $25^{\circ} \mathrm{C}$ e UR $=50 \%$. Note-se que o horário escolhido para o experimento permitiria um período de maior incidência solar. O sistema de degelo foi programado para operar a cada 12 horas.

O cálculo da carga térmica do contêiner foi desenvolvido seguindo a metodologia proposta pela ASHRAE (1994). A capacidade frigorífica do compressor foi obtida da curva de capacidade fornecida pelo fabricante, sendo de $10.500 \mathrm{~W}$ (to $=-3^{\circ} \mathrm{C}$ ). A correção da temperatura correspondente aos valores da radiação solar sobre superfícies externas de cor claro foram as seguintes: paredes Leste - Oeste, $3^{\circ} \mathrm{C}$; Norte, $2^{\circ} \mathrm{C}$; Sul, $2^{\circ} \mathrm{C}$ e para o teto, $5^{\circ} \mathrm{C}$ (ASHRAE, 1992). Estes valores foram adicionados aos diferenciais de temperatura para as referidas superfícies. Foram consideradas 18 horas de trabalho

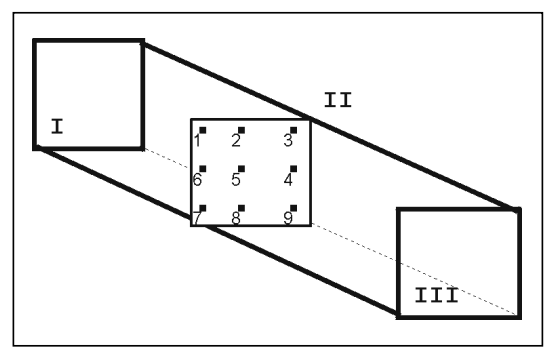

Figura 2. Representação esquemática dos pontos e planos em que foi medida a velocidade do ar no interior do contêiner. Campinas, USP-UNICAMP, 1995.

para o compressor e as seguintes condições: temperatura no interior do contêiner $\left(1^{\circ} \mathrm{C}\right)$, produto considerado (alface, $\mathrm{C}_{\mathrm{p}}=4,02 \mathrm{~kJ} / \mathrm{kg}^{\circ} \mathrm{C}$ ), quantidade $(3.289 \mathrm{~kg})$, temperatura de entrada $\left(30^{\circ} \mathrm{C}\right), \mathrm{tbu}=24^{\circ} \mathrm{C}$.

Para a determinação do tempo de resfriamento da carga de alface tipo americano (etapa II), foi feito um experimento (com duas repetições). Os produtos foram colhidos no período da manhã (aproximadamente 160 caixas), perto de Campinas, e os mesmos já tinham sido classificados por tamanho e ponto de colheita. Os produtos foram transportados em caixas plásticas de $\mathbf{5 2 8}$ x 335 x 310mm até o Laboratório de Produtos Perecíveis da FEAGRI. Depois da chegada foram escolhidas de forma aleatória três amostras por caixa, as quais foram pesadas numa balança digital. O peso médio foi de $0,9 \pm 0,01 \mathrm{~kg}$ (as caixas continham entre 10 a 12 cabeças de alface).

A distribuição das caixas no interior do contêiner foi em pilhas de $8 \times 4$ caixas, e com uma altura equivalente de 5 caixas, deixando um espaço livre entre o teto e a ultima fileira de caixas, o que possibilita o retorno do ar insuflado ao evaporador (simulando a forma em que devem ser colocadas para garantir um eficiente resfriamento).

Para monitorar a temperatura os termopares foram inseridos no centro de algumas cabeças de alface, escolhidas aleatoriamente, dispostas nas seguintes posições: a) cabeça do centro da caixa coincidindo com a pilha média do contêiner, b) cabeça colocada no centro da caixa coincidindo com a pilha próxima à porta. Estas posições permitiram conhecer o comportamento da tempe- 


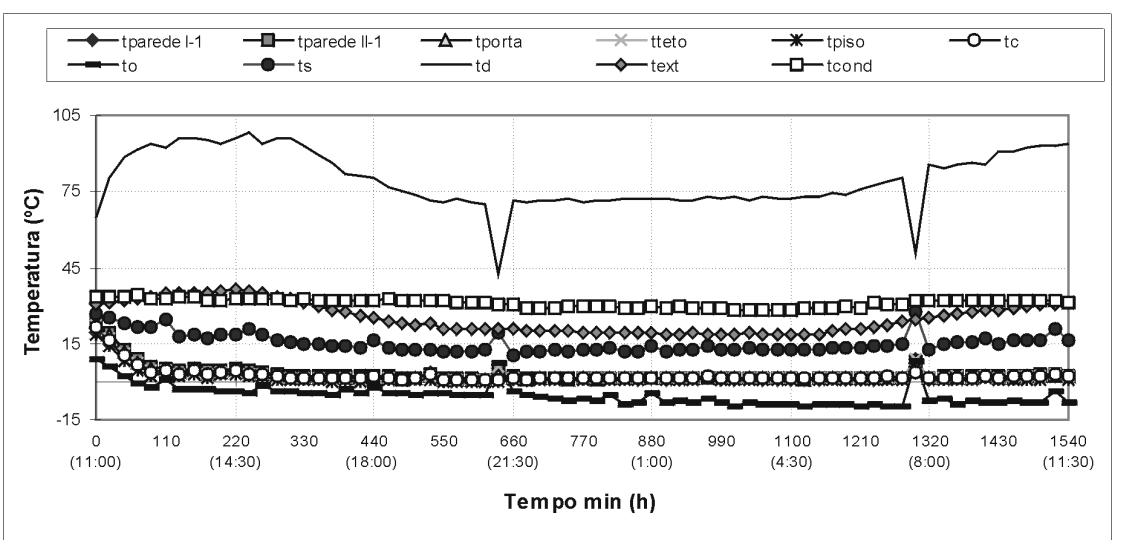

Figura 3. Comportamento da temperatura no sistema de refrigeração e no interior do contêiner vazio. Campinas, UNICAMP, 1995. tparedeI-1: temperatura na parede I, nos pontos 1, 2 e 3 da figura 1; tparedeII-1: temperatura na parede II (pto 7, 9 e 10, figura 1); tporta: temperatura na porta (pto 4 e 5 , figura 1); tteto: temperatura no teto (pto 6 , figura 1); tpiso: temperatura no piso (pto- 11, figura 1); tc: temperatura do ar na câmara (pto- 8 , figura 1); to: de evaporação do refrigerante; ts: temperatura de sução do refrigerante; td: temperatura de descarga do refrigerante; tcond- de condensação do refrigerante.

ratura do produto em áreas distintas com relação ao insuflamento do ar resfriado no evaporador. Se manteve um termopar medindo a temperatura do ar (de bulbo seco e bulbo úmido) no interior do contêiner. $\mathrm{O}$ ensaio desenvolveu-se no mês de outubro, iniciando-se às $12 \mathrm{~h} 50$ min, e com duração de $1.560 \mathrm{~min}$.

\section{RESULTADOS E DISCUSSÃO}

A temperatura do ar no insuflamento do evaporador (tc, ponto 8 , figura 1 ) atingiu $0^{\circ} \mathrm{C}$ após 3 horas do início do experimento. Em seguida a este período o compressor começou ciclos de arranque e parada com aproximadamente 5 a 8 minutos de duração, em intervalos de 25 a 30 minutos (Figura 3 ).

Como esperado, os maiores desvios dos valores da temperatura ocorreram para os pontos mais distantes do insuflamento do ar frio do evaporador. Ou seja, nas paredes I (tparede I-1, pontos $1,2,3)$ e II (tparede II-1, pontos 7, $9,10)$, na porta (tporta, pontos 4 e 5 ) e no teto (tteto, ponto 6, figura 1), mantendo diferenças muito pequenas para o piso (tpiso, ponto 11). Constatou-se que na parede I existe uma diferença de temperatura maior que na II $\left(1,5 \pm 1^{\circ} \mathrm{C}\right)$, visto que tal superfície recebe maior radiação solar.

Durante o período diurno a diferença de temperatura entre o insuflamento do ar do evaporador e os diferentes pon- tos monitorados, foi maior $\left(3 \pm 1,5^{\circ} \mathrm{C}\right)$, que no período noturno $\left(2 \pm 0,7^{\circ} \mathrm{C}\right)$. As curvas mostradas na figura 3 , correspondem-se com os valores médios de temperatura, entre os diferentes pontos monitorados.

Estes resultados demonstram o efeito da incidência solar sobre o comportamento da temperatura interior no contêiner; mesmo assim, consideramos que o contêiner possui um isolamento térmico adequado que permite ser utilizado à intempérie (diretamente no campo, ou em outra situação similar).

O nível de sobreaquecimento entre a temperatura na saída do evaporador e a temperatura de sução (ts), atingiu valores entre $18-23^{\circ} \mathrm{C}$, o que coincide com os valores referidos para sistemas frigoríficos de média capacidade que utilizam o refrigerante R-12 (entre 15 a $20^{\circ} \mathrm{C}$, ASHRAE, 1992).

Os valores da $\Delta \mathrm{T}$, diferença entre a temperatura no interior do contêiner (tc) e a temperatura de evaporação (to), permaneceram entre 6 e $8^{\circ} \mathrm{C}$. A ASHRAE (1992), recomenda valores de $\Delta \mathrm{T}$ entre 7 e $8^{\circ} \mathrm{C}$, para tais sistemas.

A diferença de temperatura entre 0 ar ambiente (text) e a temperatura de condensação (tcond), apresentou um valor médio de $10^{\circ} \mathrm{C}$, o que coincide com os valores recomendados pela ASHRAE (1992), que estabelece entre 8 e $11^{\circ} \mathrm{C}$ para condensação a ar.
Os dados experimentais empregados para o traçado do ciclo termodinâmico no diagrama Mollier foram: pressão de sução do R-12 (277 kPa, 2,32 kgf/cm²), pressão de descarga do R-12 $(958 \mathrm{kPa}$, $\left.9,77 \mathrm{kgf} / \mathrm{cm}^{2}\right)$, temperatura de descarga do $\mathrm{R}-12\left(90^{\circ} \mathrm{C}\right)$, temperatura de saída do $\mathrm{R}-12$ do condensador $\left(22^{\circ} \mathrm{C}\right)$ e nível de sobreaquecimento após a saída do evaporador $\left(18^{\circ} \mathrm{C}\right)$.

A avaliação termodinâmica do sistema de refrigeração do contêiner demonstrou que os parâmetros de operação estão dentro dos limites recomendados, o valor do COP foi de 3 , a eficiência volumétrica do compressor $\left(\eta_{\mathrm{v}}\right)$ de 0,73 .

Valores do COP entre 3 e 5 são adequados para ciclos de compressão de vapor, assim como valores de $\eta_{\mathrm{v}}$ entre 0,4 e 0,7 , demonstram que o desempenho energético da instalação é adequado (Koshkin, 1981).

A medição da velocidade do ar no interior do contêiner demonstrou que os valores mais altos correspondem aos pontos 7, 8 e 9 dos planos I e II, visto a proximidade da área do insuflamento do ar. Nos planos I e II os valores médios da velocidade do ar foram de 2,1 e 1,7 $\mathrm{m} / \mathrm{s}$, respectivamente. Estes valores foram obtidos no plano coincidente com o insuflamento do ar pelo evaporador e no meio do contêiner (Figura 2). No plano III (pontos mais perto da porta), a velocidade se manteve mais estável, com um valor médio de $0,3 \mathrm{~m} / \mathrm{s}$. A ASHRAE (1992), indica que a velocidade do ar no interior das câmaras de resfriamento não deve exceder $2,5 \mathrm{~m} / \mathrm{s}$.

$\mathrm{O}$ valor da umidade relativa variou na faixa de $80-85 \pm 1 \%$. A ASHRAE (1992) sugere que, para valores de $\Delta T$ entre 7 e $8^{\circ} \mathrm{C}$, a umidade relativa deve estar entre $81-86 \%$. Foi comprovado que os ciclos de degelo do sistema de refrigeração não afetam significativamente os valores da umidade relativa no interior do contêiner.

Com o desenvolvimento do cálculo da carga térmica se obtiveram os seguintes resultados: carga por transmissão de calor de $587 \mathrm{~W}$, carga devido a infiltração de $360 \mathrm{~W}$, carga devido aos motores de $1.948 \mathrm{~W}$, carga térmica a ser retirada dos produtos (para resfriá-los até $1^{\circ} \mathrm{C}$ ) de $5.030 \mathrm{~W}$. Observa-se que o valor da carga térmica a ser retirada dos 
produtos representa, aproximadamente, $42 \%$ da carga térmica total a ser retirada do contêiner, sendo que a carga térmica devido à radiação solar representa $0,76 \%$ da carga térmica total a ser retirada do contêiner. Como nas condições consideradas a capacidade disponível do compressor é de $10.500 \mathrm{~W}$, pode-se supor que o sistema frigorífico do contêiner é capaz de retirar carga térmica total sem dificuldades $(8.717 \mathrm{~W})$, supondo que o mesmo seja carregado com o volume de produtos que foi considerado nos cálculos.

Nos experimentos com carga real (etapa II), constatamos que o ar atingiu $1^{\circ} \mathrm{C}$ após aproximadamente $370 \mathrm{~min}$ de iniciado o experimento, partindo de uma temperatura inicial de $16^{\circ} \mathrm{C}$. Isto foi devido ao fato de que a abertura da porta para a colocação das caixas e a montagem dos termopares, fizeram com que a temperatura do ar interior que já estava a $1^{\circ} \mathrm{C}$, subisse

A temperatura inicial na superfície do produto foi de $26^{\circ} \mathrm{C}$ e no centro de $23^{\circ} \mathrm{C}$. O tempo de meio resfriamento foi atingido quando no centro das cabeças em que foram inseridos os termopares atingiu-se $11,5^{\circ} \mathrm{C}$, e isto aconteceu aproximadamente aos $530 \pm 3,5 \mathrm{~min}(8 \mathrm{ho}-$ ras) de iniciado o experimento, para as cabeças situadas na pilha 1 (centro do contêiner). Já para a pilha 2 (posição mais desfavorável com respeito a insuflamento do ar frio), o tempo de meio resfriamento foi de $1.080 \pm 3,5 \mathrm{~min}$ (18 horas), ou seja um tempo 2 vezes maior que para a pilha 1 , ponto próximo ao insuflamento do ar (Figura 4).

Os resultados obtidos demonstram que a posição dos produtos com respeito ao insuflamento do ar é muito influente em relação ao tempo de meio resfriamento, ou seja, produtos em maior contato com o fluxo de ar resfriam em menos tempo e vice-versa.

A umidade relativa permaneceu entre $90-91 \pm 1 \%$, valores 5 a $10 \%$ maio-

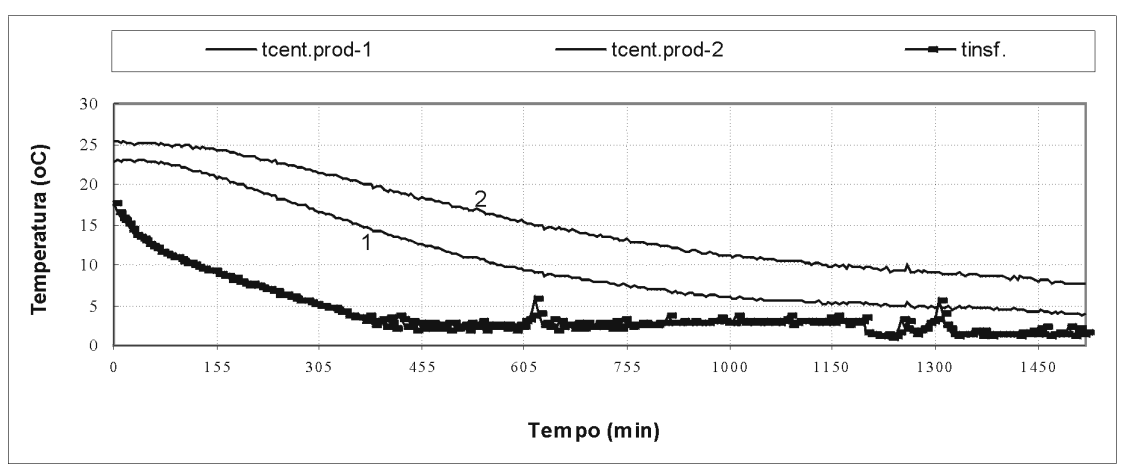

Figura 4. Tempo de resfriamento de uma carga de alface do tipo americano (Latuca sativa L.). Campinas, UNICAMP, 1995. tcent.prod-1: temperatura no centro da cabeça de alface na pilha no meio do contêiner; tcent.prod-2: temperatura no centro da cabeça de alface na pilha perto da porta do contêiner; tinsuf: temperatura do insuflamento do ar (temperatura na câmara). "

res que os obtidos nos ensaios com o contêiner vazio $(81-86 \pm 1 \%)$. Esta diferença demonstra a existência de transferência de massa entre os produtos e o ar frio, responsáveis pela perda de peso, devido ao déficit de pressão entre a superfície do produto e o ar frio. Pode-se dizer então que, o contêiner deve ser usado com cuidado para a estocagem prolongada de produtos agrícolas que exigem umidade relativa maior que $85 \%$.

O valor do tempo de meio resfriamento, unido à velocidade do ar demostram que, o contêiner não deverá ser utilizado como câmara de resfriamento rápido. No entanto estes equipamentos, poderão operar satisfatoriamente como sistema de estocagem de produtos já resfriados. Contêineres iguais ao modelo estudado, poderão ser usados na intempérie, ou seja diretamente no campo de colheita, com uma adequada eficiência.

\section{AGRADECIMENTOS}

À CAPES e à FAPESP pelo apoio financeiro. À Empresa Paulista de Contêineres Marítimos Ltda.(PCML), que cedeu o contêiner para o desenvolvimento da pesquisa.

\section{LITERATURA CITADA}

ALBRIGHT, L.D. Environment controls for animal and plants. St. Joseph, Michigan: ASAE. 1990. $453 \mathrm{p}$

ASHRAE. Handbook: Systems and equipment. Atlanta: American Society of Heating, Refrigerating and Air Conditioning Engineers. 1992. cap. 23, cap. 36 .

ASHRAE. Handbook: Systems and applications. Atlanta: American Society of Heating, Refrigerating and Air Conditioning Engineers. 1994. cap. 10, cap. 25 , cap. 26.

BRASIL. Ministério da Agricultura, Abastecimento e Reforma Agrária. Perdas na agropecuária Brasileira. Relatório preliminar. Brasília. maio, 1993.

FAO Production Yearbook. Food and Agricultural Organization. FAO Statistics Series. Roma: FAO, v. 44, n. 99, 1991.

FIGUEREDO, F. Containers frigorificos, aplicações atuais no Brasil. Associação Brasileira da Indústria de Armazenagem Frigorificada. Relatório. São Paulo. 1995

KOSHKIN, N.N. Máquinas frigorificas. Moscú. $1981.507 \mathrm{p}$.

MITCHELL, F.G The need for cooling. In: Kader, AA (ed). Postharvest Technology of Horticultural Crops. 2 ed. Oakland: University of California. p. 53-56. 1992.

NEVES FILHO, L.C.; VISSOTO, F.Z.; ALVES C.R. Resfriamento rápido de frutas e hortaliças. Revista ABRAVA. São Paulo. v. 17, n. 133, p. 22-28, 1995

TERUEL, M.B.J. Uso de containers refrigerados para o armazenamento de produtos agrícolas. Campinas: UNICAMP. 1996. 110 p. (Tese mestrado). 